\title{
Genome sequence of Acuticoccus yangtzensis JL1095T (DSM 28604T) isolated from the Yangtze Estuary
}

\author{
Lei Hou ${ }^{1,2}$, Jia Sun ${ }^{1,2}$, Xiabing Xie ${ }^{1,2}$, Nianzhi Jiao ${ }^{1,2}$ and Yao Zhang ${ }^{1,2^{*}}$
}

\begin{abstract}
Acuticoccus yangtzensis $J L_{1095}^{\top}$ is a proteobacterium from a genus belonging to the family Rhodobacteraceae; it was isolated from surface waters of the Yangtze Estuary, China. This strain displays the capability to utilize aromatic and simple carbon compounds. Here, we present the genome sequence, annotations, and features of $A$. yangtzensis $J L 1095^{\top}$. This strain has a genome size of $5,043,263$ bp with a $\mathrm{G}+\mathrm{C}$ content of $68.63 \%$. The genome contains 4286 protein-coding genes, 56 RNA genes, and 83 pseudo genes. Many of the protein-coding genes were predicted to encode proteins involved in carbon metabolism pathways, such as aromatic degradation and methane metabolism. Notably, a total of 31 genes were predicted to encode form II carbon monoxide dehydrogenases, suggesting potential for carbon monoxide oxidation. The genome analysis helps better understand the major carbon metabolic pathways of this strain and its role in carbon cycling in coastal marine ecosystems.
\end{abstract}

Keywords: Acuticoccus yangtzensis JL1095 ${ }^{\top}$, Aromatic compounds degradation, Methane metabolism, Form ॥ $\mathrm{CODH}$, Aerobic CO oxidation, Yangtze estuary

\section{Introduction}

We isolated a member in the family Rhodobacteraceae,

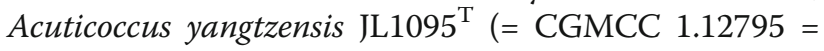
DSM 28604), from surface waters of the Yangtze Estuary, China $\left(31^{\circ} \mathrm{N}, 122^{\circ} \mathrm{E}\right)[1,2]$. The physiological properties of members in the family Rhodobacteraceae suggest that they may be important in regulating the carbon cycle in terrestrial and marine ecosystems. For instance, many members of this family can degrade aromatic compounds [3] and metabolize one-carbon compounds [4]. Physiological tests of A. yangtzensis $\mathrm{JL} 1095^{\mathrm{T}}$ have shown that strain $\mathrm{JL} 1095^{\mathrm{T}}$ was able to degrade naphthol-AS-BIphosphate, and utilize acetic acid and glycerol [1]. In addition, many members of the family Rhodobacteraceae examined to date have the ability to oxidize $\mathrm{CO}$.

$\mathrm{CO}$ is an important atmospheric trace gas that contributes to climate change despite its low concentrations $(0.05-0.12 \mathrm{ppm})$ in air [5]. Although CO is toxic

\footnotetext{
* Correspondence: yaozhang@xmu.edu.cn

${ }^{1}$ State Key Laboratory of Marine Environmental Sciences, Xiamen University, Xiamen 361102, People's Republic of China

${ }^{2}$ Institute of Marine Microbes and Ecospheres, Xiamen University, Xiamen 361102, People's Republic of China
}

for many organisms, a number of microbes can consume $\mathrm{CO}$. Marine microbial $\mathrm{CO}$ oxidation represents an important $\mathrm{CO}$ sink in the oceans. CODHs, key enzymes for $\mathrm{CO}$ oxidation, have been classified into two major types based on their cofactor composition, structure, and stability in the presence of dioxygen [6]. Ni- and Fecontaining CODHs are found in anaerobic bacteria and archaea, while $\mathrm{Cu}$ - and Mo-containing CODHs are found in aerobic bacteria [7]. Compared with the relatively hypoxic and high $\mathrm{CO}$ concentrations in the early Earth environment [8], the ecological significance of aerobic $\mathrm{CO}$ oxidation has become increasingly critical in the relatively aerobic and low $\mathrm{CO}$ concentrations in modern environments. Aerobic $\mathrm{CO}$ oxidation is carried out by phylogenetically and physiologically diverse aerobic bacteria and certain newly identified archaea that are distributed in a variety of habitats, including terrestrial, sedimentary, freshwater, and marine ecosystems [9]. The most active $\mathrm{CO}$ oxidizers belong to various genera, such as Ruegeria, Roseobacter, Stappia and Silicibacter, mostly from the family Rhodobacteraceae [10, 11]. Based on phylogenic analysis of $16 \mathrm{~S}$ rRNA sequences and physiological characteristics, A. yangtzensis $\mathrm{LL}^{1095^{\mathrm{T}}}$ is most closely related to 

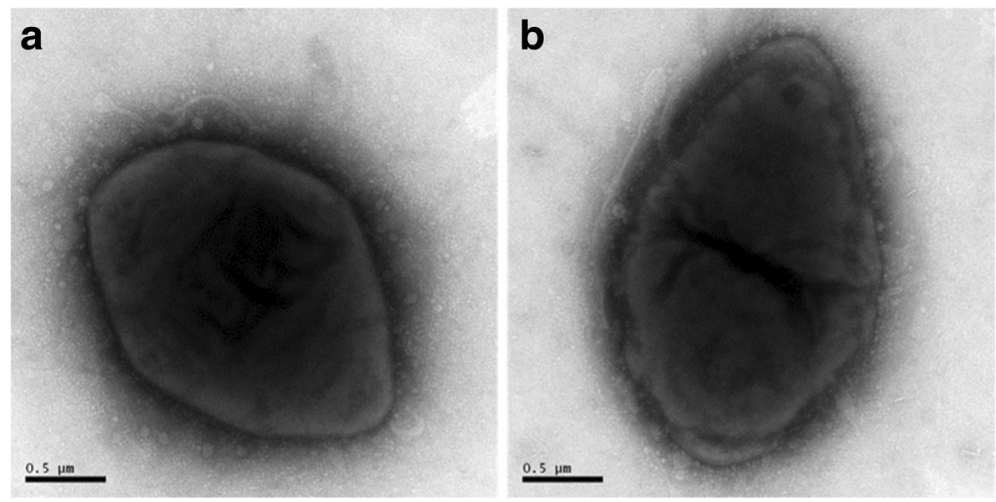

Fig. 1 Transmission electron micrographs of Acuticoccus yangtzensis JL1095 cultured on marine agar 2216 (MA; Difco) medium. a Oval-shaped cells with one peak end; $\mathbf{b}$ a cell divided by binary fission. Scale bar, $0.5 \mu \mathrm{m}$

Table 1 Classification and general features of Acuticoccus yangtzensis strain $\mathrm{LL}_{1095^{\top}}[16]$

\begin{tabular}{|c|c|c|c|}
\hline MIGS ID & Property & Term & Evidence code $\mathrm{e}^{\mathrm{a}}$ \\
\hline & Classification & Domain Bacteria & TAS [30] \\
\hline & & Phylum Proteobacteria & TAS [31] \\
\hline & & Class Alphaproteobacteria & TAS [32] \\
\hline & & Order Rhodobacterales & TAS [33] \\
\hline & & Family Rhodobacteraceae & TAS [33] \\
\hline & & Genus Acuticoccus & TAS $[1,2]$ \\
\hline & & Species Acuticoccus yangtzensis & $\operatorname{TAS}[1,2]$ \\
\hline & & Type strain: JL1095 ${ }^{T}$ (= CGMCC $1.12795=$ DSM 28604) & \\
\hline & Gram stain & Negative & TAS [1] \\
\hline & Cell shape & Oval-shaped with one peak end & TAS [1] \\
\hline & Motility & Motile & TAS [1] \\
\hline & Sporulation & Not reported & NAS \\
\hline & Temperature range & $15-50^{\circ} \mathrm{C}$ & TAS [1] \\
\hline & Optimum temperature & $35^{\circ} \mathrm{C}$ & TAS [1] \\
\hline & $\mathrm{pH}$ range; Optimum & $6.0-9.0 ; 7.6$ & TAS [1] \\
\hline & Carbon source & $\begin{array}{l}\text { Tween } 40 \text {, Tween } 80 \text {, L-arabinose, methyl-pyruvate, D, L-Lactic acid, } \\
\text { acetic acid, urocanic acid, a-hydroxy butyric acid, } \beta \text {-hydroxy } \\
\text { butyric acid and } \gamma \text {-hydroxy butyric acid }\end{array}$ & TAS [1] \\
\hline MIGS-6 & Habitat & Estuary & TAS [1] \\
\hline MIGS-6.3 & Salinity & $2-10 \% \mathrm{NaCl}(w / v)$ & TAS [1] \\
\hline MIGS-22 & Oxygen requirement & Aerobic & TAS [1] \\
\hline MIGS-15 & Biotic relationship & free-living & NAS \\
\hline MIGS-14 & Pathogenicity & Non-pathogen & NAS \\
\hline MIGS-4 & Geographic location & Yangtze Estuary, China & TAS [1] \\
\hline MIGS-5 & Sample collection & January 2006 & IDA \\
\hline MIGS-4.1 & Latitude & $31^{\circ} \mathrm{N}$ & TAS [1] \\
\hline MIGS-4.2 & Longitude & $122^{\circ} \mathrm{E}$ & TAS [1] \\
\hline MIGS-4.4 & Altitude & Sea level & TAS [1] \\
\hline
\end{tabular}

a Evidence codes - IDA Inferred from Direct Assay, TAS Traceable Author Statement (i.e., a direct report exists in the literature), NAS Non-traceable Author Statement (i.e., not directly observed for the living, isolated sample, but based on a generally accepted property for the species, or anecdotal evidence). These evidence codes are from the Gene Ontology project [22] 
the genus Stappia [1], in which all known and examined to date have the ability to oxidize $\mathrm{CO}$, containing form I and II cox gene operons [12-14].

In this study, we describe the classification and features of A. yangtzensis $\mathrm{LL}_{1095^{\mathrm{T}}}$, report its first draft genome sequence, and explore its major carbon metabolic pathways and potential capability to oxidize $\mathrm{CO}$.

\section{Organism information \\ Classification and features}

A. yangtzensis $\mathrm{JL} 1095^{\mathrm{T}}$ (= CGMCC $1.12795=\mathrm{DSM}$ 28604), as the type strain of $A$. yangtzensis in the family Rhodobacteraceae, is a Gram-negative, aerobic, motile (possibly through gliding), oval-shaped with one peak end bacterium (Fig. 1). The detailed classification and features were previously reported $[1,2]$. Briefly, the solocarbon-source utilization test indicated that Tween 40, Tween 80, L-arabinose, methyl-pyruvate, $\beta$-hydroxy butyric acid, D,L-lactic acid, acetic acid, urocanic acid, $\alpha$-hydroxy butyric acid, $\gamma$-hydroxy butyric acid, Lproline, glycerol, $\alpha$-keto butyric acid, D-fructose, Lfucose, D-galactose, $\alpha$-D-glucose, D-mannose, L-serine, $\mathrm{D}$-sorbitol, D-gluconic acid, $\alpha$-keto glutaric acid, succinamic acid, L-glutamic acid, pyruvate, and gelatin were utilized by this strain. In addition, strain $\mathrm{JL} 1095^{\mathrm{T}}$ produces various enzymes for the degradation of organic matter, including urease, protease, alkaline phosphatase enzyme, esterase (C4), leucine arylamidase, valine arylamidase, trypsin and naphthol-AS-BI-phosphate hydrolase [1]. The current classification and general features of A. yangtzensis $\mathrm{JL} 1095^{\mathrm{T}}$ are listed in Table 1.

The draft genome sequence of A. yangtzensis $\mathrm{JL} 1095^{\mathrm{T}}$ has one full-length $16 \mathrm{~S}$ rRNA gene sequence (1450 bp; BIX52_RS22260) that was consistent with the partial 16S rRNA gene sequence from the original species description (1397 bp; KF741873) [1]. Strain JL1095 ${ }^{\mathrm{T}}$ showed the highest 16S rRNA gene sequence similarity with Stappia indica $\mathrm{B} 106^{\mathrm{T}}$ (92.7\%) followed by Stappia stellata IAM $12621^{\mathrm{T}}(92.6 \%)$ and Labrenzia suaedae DSM $22153^{\mathrm{T}}$ (92.3\%). The phylogenetic tree was constructed to assess the evolutionary relationships between strain $\mathrm{JL} 1095^{\mathrm{T}}$ and other related strains with the MEGA 5.05 software by using a neighbor-joining algorithm with the Jukes-Cantor model. The phylogeny of the strain $\mathrm{JL} 1095^{\mathrm{T}}$ illustrated that one monophyletic branch is formed at the periphery of the evolutionary radiation occupied by the various genera in the family Rhodobacteraceae (Fig. 2).

\section{Genome sequencing information \\ Genome project history}

This strain was selected for sequencing on the basis of its important evolutionary position, the degradation of aromatic and simple hydrocarbon compounds via metabolism [1], and its potential CO oxidation ability. The

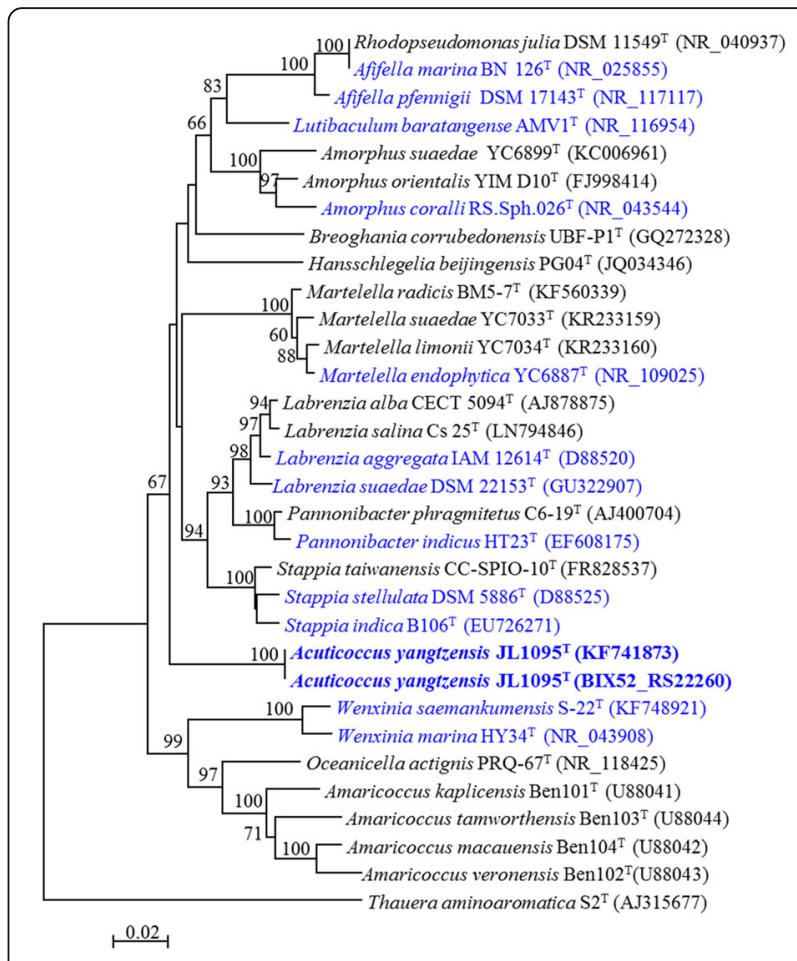

Fig. 2 Phylogenetic tree illustrating the relationship between Acuticoccus yangtzensis $J 11095^{\top}$ and other validly published species. The tree was constructed with MEGA 5.05 software by using the neighbor-joining (NJ) method for $16 \mathrm{~S}$ rRNA gene sequences. Accession numbers in the GenBank database are shown in parentheses. Reference sequences from relative strains that has been sequenced and obtained a public genome are in blue font, while the $J \mathrm{~L}_{1095}{ }^{\mathrm{T}}$ sequence is in blue bold font. The numbers at the nodes indicate bootstrap percentages based on 1000 replicates; only values higher than $50 \%$ are shown. Bar, 0.02 substitutions per nucleotide position. Thauera aminoaromatica $S 2^{\top}$ was used to root the tree

sequencing of the A. yangtzensis $\mathrm{JL} 1095^{\mathrm{T}}$ genome was carried out at Beijing Novogene Bioinformatics Technology Co., Ltd. The genome sequence of A. yangtzensis JL1095 ${ }^{\mathrm{T}}$ has been deposited in the GOLD [15] and DDBJ/EMBL/ GenBank under accession number MJUX00000000. A summary for the genome sequencing information of $A$. yangtzensis $\mathrm{JL} 1095^{\mathrm{T}}$ is listed in Table 2 , in compliance with MIGS version 2.0 [16].

\section{Growth conditions and genomic DNA preparation}

A. yangtzensis $\mathrm{JL} 1095^{\mathrm{T}}$ (= CGMCC $1.12795=\mathrm{DSM}$ 28604) was cultivated aerobically in MB (Difco) medium. The genomic DNA of strain $\mathrm{JL1095}^{\mathrm{T}}$ was extracted using the Tguide Bacteria Genomic DNA Kit (OSRM502, TIANGEN Biotech Co. Ltd., Beijing, China) in accordance with the instruction manual. After this strain was cultivated in $\mathrm{MB}$ medium in the shaker at $35^{\circ} \mathrm{C}$ for 2-3 days, the total DNA obtained was subjected to quality control by agarose gel electrophoresis and quantified by Qubit 2.0 fluorometer (Life Technologies, MA, USA). 
Table 2 Project information

\begin{tabular}{lll}
\hline MIGS ID & Property & Term \\
\hline MIGS 31 & Finishing quality & High-quality draft \\
MIGS-28 & Libraries used & 500 bp Paired-end \\
MIGS 29 & Sequencing platforms & Illumina HiSeq 2500 \\
MIGS 31.2 & Fold coverage & $331 X$ \\
MIGS 30 & Assemblers & SOAPdenovo version 2.04 \\
MIGS 32 & Gene calling method & GeneMarkS version 4.17 \\
& Locus Tag & BIX52 \\
& Genbank ID & MJUX00000000 \\
& GenBank Date of Release & December 31th, 2016 \\
& GOLD ID & Gp0206530 \\
& BIOPROJECT & PRJNA343888 \\
MIGS 13 & Source Material Identifier & CGMCC 1.12795=DSM 28604 \\
& Project relevance & Environmental, microbes \\
\hline
\end{tabular}

\section{Genome sequencing and assembly}

The genome sequencing of this strain was conducted using Illumina HiSeq 2500 paired-end sequencing technology under the PE 150 strategy. A total filtered read size of $1674 \mathrm{Mbp}$ was obtained. The filtered reads were assembled by SOAPdenovo version 2.04 software and 29 contigs were generated [17, 18]. Gene prediction was performed on the genome assembly using GeneMarkS version 4.17 [19].

\section{Genome annotation}

Functional annotation of the coding sequences was performed by searching various databases (KEGG [20], NR, COG [21], and GO [22]). The rRNA genes of strain JL1095 ${ }^{\mathrm{T}}$ were predicted using rRNAmmer software [23], tRNA genes were identified using tRNAscan-SE [24], and SRNA were predicted by BLAST searches against the Rfam database [25]. The online CRISPRFinder program was used for CRISPR identification [26].

\section{Genome properties}

The A. yangtzensis $\mathrm{JL} 1095^{\mathrm{T}}$ genome was composed of $5,043,263$ bp with a $\mathrm{G}+\mathrm{C}$ content of $68.63 \%$. A total of 4286 protein-coding genes were predicted with an average length of $994 \mathrm{bp}$, occupying $87.01 \%$ of the genome. The genome also contained 56 RNA genes and 83 pseudo genes. Detailed genome statistical information is shown in Table 3. COG categories were assigned to 2522 of the protein-coding genes which were classified into 21 functional groups. The most dominant COG categories were "amino acid transport and metabolism" followed by "general function prediction only", "function unknown", and "energy production and conversion". Detailed gene numbers and percentages related with the COG categories are shown in Table 4. In total, 2470
Table 3 Genome statistics

\begin{tabular}{lll}
\hline Attribute & Value & \% of Total \\
\hline Genome size (bp) & $5,043,263$ & 100.00 \\
DNA coding (bp) & $4,388,143$ & 87.01 \\
DNA G + C (bp) & $3,461,191$ & 68.63 \\
DNA scaffolds & 28 & 100.00 \\
Total genes & 4425 & 100.00 \\
Protein coding genes & 4286 & 96.86 \\
RNA genes & 56 & 1.27 \\
Pseudo genes & 83 & 1.88 \\
Genes in internal clusters & NA & NA \\
Genes with function prediction & 3781 & 85.45 \\
Genes assigned to COGs & 2522 & 56.99 \\
Genes with Pfam domains & 3139 & 70.94 \\
Genes with signal peptides & 348 & 7.86 \\
Genes with transmembrane helices & 1043 & 23.57 \\
CRISPR repeats & 3 & 0.07 \\
\hline
\end{tabular}

$N A$, no analysis

Table 4 Number of genes associated with general COG functional categories

\begin{tabular}{lllll}
\hline Code & Value & \%age & Description \\
\hline J & 162 & 3.78 & Translation, ribosomal structure and biogenesis \\
A & 0 & 0.00 & RNA processing and modification \\
K & 139 & 3.24 & Transcription \\
L & 111 & 2.59 & Replication, recombination and repair \\
B & 3 & 0.07 & Chromatin structure and dynamics \\
D & 19 & 0.44 & Cell cycle control, Cell division, chromosome \\
& & & partitioning \\
V & 20 & 0.47 & Defense mechanisms \\
T & 93 & 2.17 & Signal transduction mechanisms \\
M & 126 & 2.94 & Cell wall/membrane biogenesis \\
N & 30 & 0.70 & Cell motility \\
U & 43 & 1.00 & Intracellular trafficking and secretion \\
O & 111 & 2.59 & Posttranslational modification, protein turnover, \\
& & & chaperones \\
C & 223 & 5.20 & Energy production and conversion \\
G & 198 & 4.62 & Carbohydrate transport and metabolism \\
E & 388 & 9.05 & Amino acid transport and metabolism \\
F & 63 & 1.47 & Nucleotide transport and metabolism \\
H & 122 & 2.85 & Coenzyme transport and metabolism \\
I & 138 & 3.22 & Lipid transport and metabolism \\
P & 187 & 4.36 & Inorganic ion transport and metabolism \\
Q & 109 & 2.54 & Secondary metabolites biosynthesis, transport and \\
& & & catabolism \\
R & 378 & 8.82 & General function prediction only \\
S & 232 & 5.41 & Function unknown \\
- & 1764 & 41.16 & Not in COGs \\
\hline & & &
\end{tabular}

The total is based on the total number of protein coding genes in the genome 


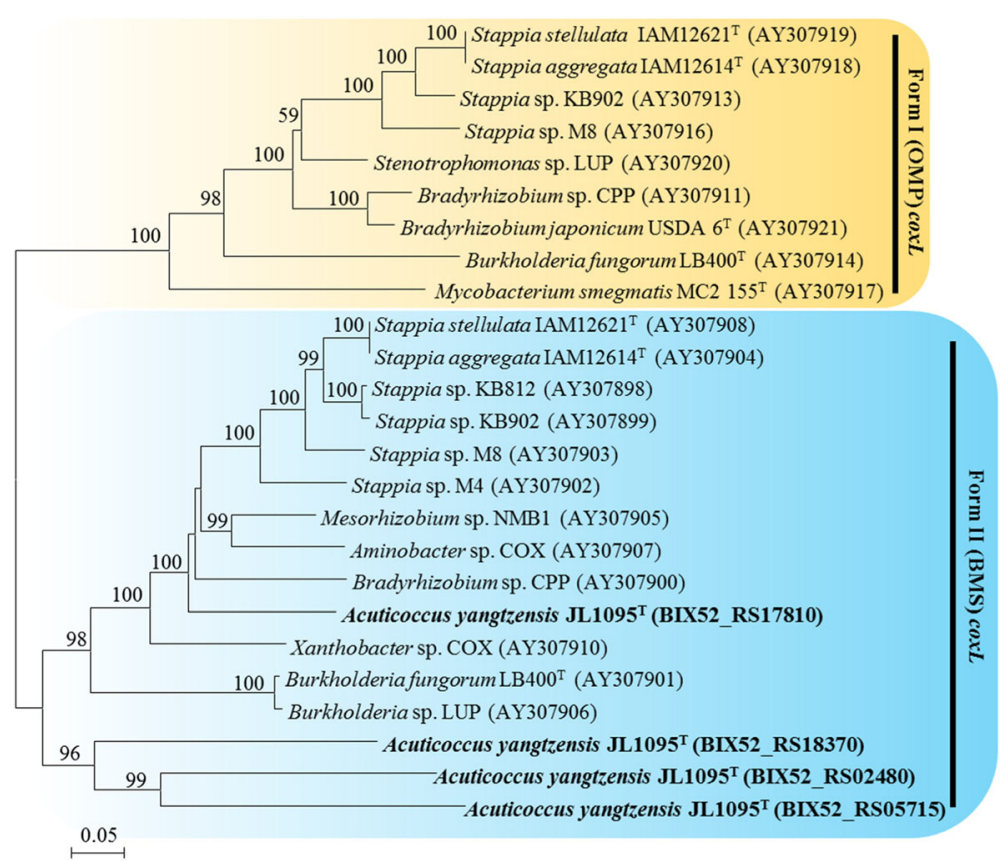

Fig. 3 Unrooted phylogenetic tree showing the coxL genetype of Acuticoccus yangtzensis JL1095 ${ }^{\top}$. The tree was constructed with MEGA 5.05 software by using the neighbor-joining (NJ) method based on the form I coxL and form II putative coxL genes from CO-oxidizing microbes. Accession numbers in the GenBank database are shown in parentheses. The coxL genes encoded in the Acuticoccus yangtzensis JL1095 ${ }^{\top}$ genome are shown in bold. Sequences in orange and blue shades represent form I and II coxL genes, respectively. The numbers at the nodes indicate bootstrap percentages based on 1000 replicates; only values higher than $50 \%$ are shown. Bar, 0.05 substitutions per nucleotide position

protein-coding genes were assigned to 153 KEGG metabolic pathways, including key genes involved in carbon metabolism processes such as gluconeogenesis, polycyclic aromatic hydrocarbon degradation, and methane metabolism. In addition, based on the GO database, 1992 protein-coding genes were assigned to molecular function, 1394 genes were assigned to cellular components, and 2646 genes were assigned to biological processes.

\section{Insights from the genome sequence}

We performed a systematic analysis of the proteincoding genes with functional predictions by BLAST searches against the four databases (KEGG, NR, COG, and GO), with E-value $<1 \mathrm{e}-5$ and minimal alignment length of $>40 \%$.

Strain $\mathrm{JL} 1095^{\mathrm{T}}$ was predicted to contain most of the genes central to carbon metabolism, including those related to glycolysis/gluconeogenesis, the tricarboxylic acid cycle, and the pentose phosphate pathway. Furthermore, about 198 genes were assigned to COG categories related to carbohydrate transport and metabolism, including fructose, mannose, and galactose metabolism. These carbohydrate metabolic characteristics are generally coincident with those obtained from a sole-carbon-source utilization experiment [1]. The capacity of this strain to degrade aromatic compounds such as naphthol-AS-BIphosphate has been identified. Approximately 236 genes were involved in 13 KEGG metabolic pathways related to aromatic compounds degradation, such as polycyclic aromatic hydrocarbon, bisphenol, and naphthalene. Aromatic compounds are important environmental organic pollutants because of their persistence in environments, toxicity, and carcinogenic characteristics [27]. Furthurmore, strain $\mathrm{JL}_{1095^{\mathrm{T}}}$ was annotated to contain 48 genes related to methane metabolism.

Based on results from the four functional annotation databases, the A. yangtzensis $\mathrm{JL} 1095^{\mathrm{T}}$ genome contained a total of 31 genes predicted to encode aerobic-type CODHs (Additional file 1: Table S1). The cox gene clusters that encode aerobic CODHs have been classified into two major forms based on genome analysis [9]. Form I genes are mainly from Oligotropha, Mycobacterium and Pseudomonas, and form II putative genes are mainly from Bradyrhizobium, Mesorhizobium, and Sinorhizobium [13]. Form I and II cox gene operons consisted of three conserved structural genes that were transcribed as coxMSL and coxSLM, respectively [28, 29]. For strain $\mathrm{JL} 1095^{\mathrm{T}}$, three structural genes containing coxS (small subunit), $\operatorname{cox} M$ (medium subunit) and $\operatorname{coxL}$ (large subunit) were all sequenced. Form I $\operatorname{cox} S$ and $\operatorname{cox} M$ gene sequences were similar to form II $\operatorname{coxS}$ and $\operatorname{cox} M$ gene sequences, but the form II putative cox $L$ gene sequence was approximately $40-50 \%$ similar to the form I coxL gene sequence [9]. Therefore, the coxL gene has been used as a molecular 
biomarker to explore the distribution of aerobic $\mathrm{CO}$ bacteria in ecosystems [29]. We constructed the coxL phylogenetic tree for strain $\mathrm{JL} 1095^{\mathrm{T}}$ and confirmed that four predicted $\operatorname{coxL}$ genes (Locus tag: BIX52_RS02480, BIX52_RS05715, BIX52_RS17810 and BIX52_RS18370) were recognized as form II coxL genes (Fig. 3). Additionally, the accessory genes were also essential for $\mathrm{CO}$ oxidation to take place. The accessory genes in forms I and II varied substantially, and even within the same form, the order and subunit types varied among isolates [9]. Form I cox accessory genes, including $\operatorname{cox} B, C, G, H, I$, and $K$, were distributed flexibly around the structural genes. Among the form II cox accessory genes, $\operatorname{cox} G$ was usually an indispensable gene compared with other accessory genes, such as $\operatorname{cox} D, E$, and $F$ [28]. For this strain, the accessory gene $\operatorname{cox} G$ was detected. Form I $\mathrm{CODH}$ has been specifically characterized for its ability to oxidize $\mathrm{CO}$, while form II is a putative $\mathrm{CODH}$ and its ability to oxidize $\mathrm{CO}$ remains uncertain. For the Roseobacter clade, both coxL forms were present, which enables them to oxidize $\mathrm{CO}$ [11]. Phylogenetic analysis using the $16 \mathrm{~S}$ rRNA gene sequences of $A$. yangtzensis $\mathrm{JL} 1095^{\mathrm{T}}$ and Roseobacter clade bacteria indicates that $\mathrm{L} 1095^{\mathrm{T}}$ does not belong to the Roseobacter clade (Fig. 4). However, many other bacteria containing only form II cox genes have been shown by molecular and culture-based methods to oxidize $\mathrm{CO}$, including Mesorhizobium sp. strain NMB1, Mesorhizobium loti, Aminobacter sp. strain COX, Xanthobacter sp. strain COX, and Burkholderia sp. strain LUP [13]. According to the phylogenetic tree (Fig. 3), the $\operatorname{coxL}$ genes of $J \mathrm{~L} 1095^{\mathrm{T}}$

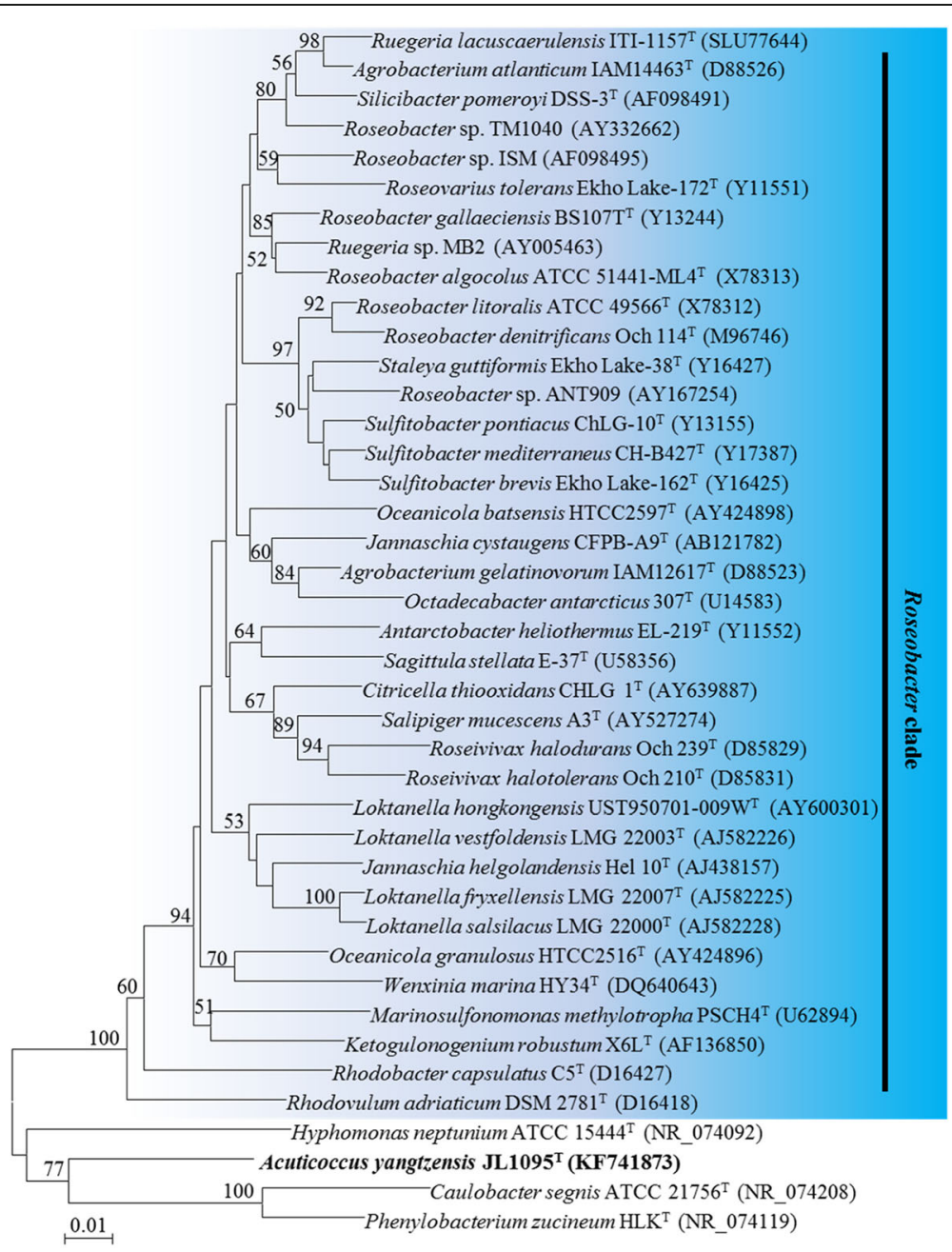

Fig. 4 Unrooted phylogenetic tree displaying the relationship between Acuticoccus yangtzensis $J 1095^{\top}$ and Roseobacter clade bacteria. The tree was constructed with MEGA 5.05 software by using the neighbor-joining ( $N J$ ) method based on 16S rRNA gene sequences. Accession numbers in the GenBank database are shown in parentheses. The $16 \mathrm{~S}$ rRNA gene encoded in the Acuticoccus yangtzensis JL1095 genome is shown in bold. The numbers at the nodes indicate bootstrap percentages based on 1000 replicates; only values higher than 50\% are shown. Bar, 0.01 substitutions per nucleotide position 
clustered tightly with these bacterial isolates. Thus, we speculate that JL1095 ${ }^{\mathrm{T}}$ is capable of oxidizing CO. Future studies are needed to determine its function in $\mathrm{CO}$ oxidation.

\section{Conclusions}

In the present study, the genome of A. yangtzensis $\mathrm{JL}_{1095}{ }^{\mathrm{T}}$, the type strain of $A$. yangtzensis, was characterized. It contains numerous genes involved in carbohydrate transport and metabolism, aromatic compounds degradation, and methane metabolism. Knowledge of the genome sequence of A. yangtzensis $\mathrm{JL} 1095^{\mathrm{T}}$ lays a foundation for better understanding the carbon metabolism of this strain. Based on genome analysis, we speculate that $\mathrm{JL} 1095^{\mathrm{T}}$ is capable of oxidizing CO. Future studies are needed to determine its function in $\mathrm{CO}$ oxidation. These genomic data provide insight into the carbon metabolic characteristics of A. yangtzensis $\mathrm{JL} 1095^{\mathrm{T}}$ and its role in alleviating coastal water pollution and effects on the marine carbon cycle.

\section{Additional file}

Additional file 1: Table S1. Aerobic-type CODH-encoding genes of Acuticoccus yangtzensis $J L_{1095^{\top}}$ predicted using four different databases. (DOCX $29 \mathrm{~kb})$

\section{Abbreviations \\ CGMCC: China General Microbiological Culture Collection Center; CO: Carbon monoxide; CODHs: CO dehydrogenases; CRISPR: Clustered regularly interspaced short palindromic repeats; DSMZ: Leibniz-Institut DSMZ - Deutsche Sammlung von Mikroorganismen und Zellkulturen $\mathrm{GmbH}$; GOLD: Genomes OnLine Database; MA: marine agar 2216; MB: marine broth 2216; MIGS: Minimum information on the genome sequence}

\section{Funding}

This research was supported by the SOA projects GASI-03-01-02-03, the national key research program 2016YFA0601400, the NSFC projects $41,422,603,41,676,125$, and $91,428,308$.

\section{Authors' contributions}

This project was founded by $Y Z$ and NJ. The main tasks, including experiments, data analysis and manuscript writing, were performed by LH and YZ. JS was associated with this bacteria isolation. XX provided technical support for this research. All authors read and approved the final manuscript.

\section{Competing interests}

The authors declare that they have no competing interests.

\section{Publisher's Note}

Springer Nature remains neutral with regard to jurisdictional claims in published maps and institutional affiliations.

Received: 12 July 2017 Accepted: 5 December 2017

Published online: 29 December 2017

\section{References}

1. Hou L, Zhang Y, Sun J, Xie X. Acuticoccus yangtzensis gen. nov., sp. nov., a novel member in the family Rhodobacteraceae, isolated from the surface water of the Yangtze estuary. Curr Microbiol. 2015;70:176-82.
2. Oren A, Garrity GM. List of new names and new combinations previously effectively, but not validly, published. Int I Syst Evol Microbiol. 2017:67:1095-8.

3. Buchan A, Neidle EL, Moran MA. Diversity of the ring-cleaving dioxygenase genepcaH in a salt marsh bacterial community. Appl Environ Microbiol. 2001:67:5801-9.

4. Doronina NV, Trotsenko YA, Tourova TP. Methylarcula marina gen. nov., sp. nov. and Methylarcula terricola sp. nov: novel aerobic, moderately halophilic, facultatively methylotrophic bacteria from coastal saline environments. Int J Syst Evol Microbiol. 2000;50:1849-59.

5. Air quality guidelines for Europe (Second edition). 2000. http://hdl.handle. net/20.500.11822/8681. Accessed 2000.

6. Jeoung JH, Dobbek H. Carbon dioxide activation at the Ni, Fe-cluster of anaerobic carbon monoxide dehydrogenase. Science. 2007;318:1461-4.

7. Ragsdale SW. Life with carbon monoxide. Crit Rev Biochem Mol Biol. 2004:39:165-95.

8. Miyakawa S, Yamanashi H, Kobayashi K, Cleaves HJ, Miller SL. Prebiotic synthesis from CO atmospheres: implications for the origins of life. Proc Natl Acad Sci. 2002;99:14628-31.

9. King GM, Weber CF. Distribution, diversity and ecology of aerobic COoxidizing bacteria. Nat Rev Microbiol. 2007;5:107-18.

10. Tolli JD, Sievert SM, Taylor CD. Unexpected diversity of bacteria capable of carbon monoxide oxidation in a coastal marine environment, and contribution of the Roseobacter-associated clade to total CO oxidation. Appl Environ Microbiol. 2006;72:1966-73.

11. Zhang Y, Sun Y, Jiao N, Stepanauskas R, Luo H. Ecological genomics of the uncultivated marine Roseobacter lineage CHAB-I-5. Appl Environ Microbiol. 2016:82:2100-11.

12. Kim BC, Park JR, Bae JW, Rhee SK, Kim KH, Oh JW, et al. Stappia marina sp. nov., a marine bacterium isolated from the Yellow Sea. Int I Syst Evol Microbiol. 2006;56:75-9.

13. King GM. Molecular and culture-based analyses of aerobic carbon monoxide oxidizer diversity. Appl Environ Microbiol. 2003;69:7257-65.

14. Weber CF, King GM. Physiological, ecological, and phylogenetic characterization of Stappia, a marine CO-oxidizing bacterial genus. Appl Environ Microbiol. 2007;73:1266-76.

15. Liolios K, Mavromatis K, Tavernarakis N, Kyrpides NC. The Genomes On Line Database (GOLD) in 2007: status of genomic and metagenomic projects and their associated metadata. Nucleic Acids Res. 2008;36(Suppl 1):475-9.

16. Field D, Garrity G, Gray T, Morrison N, Selengut J, Sterk P, et al. The minimum information about a genome sequence (MIGS) specification. Nat Biotechnol. 2008;26:541-7.

17. Li R, Li Y, Kristiansen $K$, Wang J. SOAP: short oligonucleotide alignment program. Bioinformatics. 2008;24:713-4.

18. Li R, Zhu H, Ruan J, Qian W, Fang X, Shi Z, et al. De novo assembly of human genomes with massively parallel short read sequencing. Genome Res. 2010;20:265-72.

19. Besemer J, Lomsadze A, Borodovsky M. GeneMarkS: a self-training method for prediction of gene starts in microbial genomes. Implications for finding sequence motifs in regulatory regions. Nucleic acids Res. 2001;29:2607-18.

20. Kanehisa M, Goto S, Kawashima S, Okuno Y, Hattori M. The KEGG resource for deciphering the genome. Nucleic Acids Res. 2004;32:277-80.

21. Tatusov RL, Fedorova ND, Jackson JD, Jacobs AR, Kiryutin B, Koonin EV, et al. The COG database: an updated version includes eukaryotes. BMC bioinformatics. 2003:4:1-14.

22. Ashburner M, Ball CA, Blake JA, Botstein D, Butler H, Cherry JM, et al. Gene Ontology: tool for the unification of biology. Nat Genet. 2000;25:25-9.

23. Lagesen $\mathrm{K}$, Hallin PF, Rødland E, Stærfeldt HH, Rognes T, Ussery DW. RNammer: consistent annotation of rRNA genes in genomic sequences. Nucleic Acids Res. 2007:35:3100-8.

24. Lowe TM, Eddy SR. tRNAscan-SE: a program for improved detection of transfer RNA genes in genomic sequence. Nucleic acids Res. 1997;25:955-4.

25. Gardner PP, Daub J, Tate JG, Nawrocki EP, Kolbe DL, Lindgreen S, et al. Rfam: updates to the RNA families database. Nucleic acids Res. 2009;37:136-40.

26. Grissa I, Vergnaud G, Pourcel C. CRISPRFinder: a web tool to identify clustered regularly interspaced short palindromic repeats. Nucleic acids research. 2007;35(Suppl 2):52-7.

27. Liu Y, Chen L, Jianfu Z, Qinghui H, Zhiliang Z, Hongwen G. Distribution and sources of polycyclic aromatic hydrocarbons in surface sediments of rivers and an estuary in Shanghai. China. Environ Pollut. 2008;154:298-305. 
28. Santiago B, Schübel U, Egelseer C, Meyer O. Sequence analysis, characterization and $\mathrm{CO}$-specific transcription of the cox gene cluster on the megaplasmid pHCG3 of oligotropha carboxidovorans. Gene. 1999:236:115-24.

29. Yang J, Zhou E, Jiang H, Li W, Wu G, Huang L, et al. Distribution and diversity of aerobic carbon monoxide-oxidizing bacteria in geothermal springs of China, the Philippines, and the United States. Geomicrobiol J. 2015;32:903-13.

30. Woese CR, Kandler O, Wheelis ML. Towards a natural system of organisms: proposal for the domains Archaea, Bacteria, and Eucarya. Proc Natl Acad Sci. 1990:87:4576-9.

31. Stackebrandt E, Murray RGE, Truper HG. Proteobacteria classis nov., a name for the phylogenetic taxon that includes the "purple bacteria and their relatives". Int J Syst Bacteriol. 1988;38:321-5.

32. Garrity GM, Bell JA, Lilburn T. Class I. Alphaproteobacteria class. nov. In: Brenner DJ, Krieg NR, Staley JT, Garrity GM, editors. Bergeys Manual of Systematic Bacteriology, second edition, vol. 2 (The Proteobacteria), part C (The Alpha-, Beta-, Delta-, and Epsilonproteobacteria). New York: Springer; 2005. p. 1.

33. Garrity GM, Bell JA, Lilburn T. Family I. Rhodobacteraceae fam. nov. In: Garrity GM, Brenner DJ, Krieg NR, Staley JT, editors. Bergey's Manual of Systematic Bacteriology, second edition, vol. 2, part C. New York: Springer; 2005. p. 161

Submit your next manuscript to BioMed Central and we will help you at every step:

- We accept pre-submission inquiries

- Our selector tool helps you to find the most relevant journal

- We provide round the clock customer support

- Convenient online submission

- Thorough peer review

- Inclusion in PubMed and all major indexing services

- Maximum visibility for your research

Submit your manuscript at www.biomedcentral.com/submit
Biomed Central 